\title{
How does imposing a step-by-step solution method impact students' approach to mathematical word problem solving?
}

\author{
Marie-Pier Goulet-Lyle (San Diego French American School) \\ Dominic Voyer (Université du Québec à Rimouski) \\ Lieven Verschaffel (KU Leuven)
}

\begin{abstract}
This paper presents the second phase of a larger research program with the purpose of exploring the possible consequences of a gap between what is done in the classroom regarding mathematical word problem solving and what research shows to be effective in this particular field of study. Data from the first phase of our study on teachers' self-proclaimed practices showed that one-third of elementary teachers from the region of Quebec require their students to follow a specific sequential problemsolving method, known as the 'what I know, what I look for' method. These results led us to hypothesize that the observed gap may have an impact on students' comprehension of mathematical word problems. The use of this particular method was the foundation for us to study, in the second phase, the effect of the imposition of this sequential method on students' literal and inferential understanding of word problems. A total of 278 fourth graders (9-10 years old) solved mathematical word problems followed by a test to assess their understanding of the word problems they had just solved. The results suggest that the use of this problem solving method does not seem to improve or impair students' understanding. From a more fundamental point of view, our study led us to the conclusion that the way word problem solving is addressed in the mathematics classroom, through sequential and inflexible methods, does not help students develop their word problem solving competence.
\end{abstract}

\section{Introduction}

Probably the most commonly used model for solving mathematical word problems at the elementary level is Pólya's four-step model, presented for the first time in the book How to solve it (1945). The four steps of this model are as follows:

(1) understand the problem, (2) make a plan, (3) carry out the plan, and (4) look back to check the results (Reys et al. 2012; Schoenfeld 1992; Verschaffel et al. 2000; Wilson et al. 1993).

Several curricula documents, such as the research-based evidence guide to effective instruction in mathematics writ- ten by the Ontario Ministry of Education (2006), explicitly acknowledged the importance of Pólya's model in teaching word problem solving, and emphasize that it should be introduced already in elementary school as a guide to help students, from a young age on, solving these problems in a thoughtful and systematic way. However, Reys et al. (2012) emphasized that Pólya's four-step model provides only a general overview of working through the problem solving process. Except for very simple problems, it is seldom possible to follow the steps as linearly and straightforwardly as presented by the model. At the same time, they added that in some cases all the steps defined by the model are not necessary, while in other cases stages may occur simultaneously. In Quebecer ${ }^{1}$ mathematics textbooks and activity books for elementary school students, different publishers, such as CEC Publishing and Pearson ERPI, present a common method of problem

\footnotetext{
${ }^{1}$ People living in the province of Quebec in Canada
} 
solving, which is known as the "what I know, what I look for" method. Although the authors of these textbooks and activity books do not explicitly refer to the work of Pólya, it seems clear that this method is inspired by his work.

The Quebecer method, similarly to most problem solving methods, has two main steps: comprehension and solving. The comprehension step is in its turn divided into two parts, 'what I know' and 'what I look for', while the resolution step involves the question 'what I am doing'. Very few publications exist about this method and its use. In fact, to the best of our knowledge, the only information available is what is provided by these Quebecer mathematics textbooks, which describe a word problem solving process that is more sequential than cyclical, consisting of the three steps mentioned above that must be done in the given specific order, i.e., (1) what I know, (2) what I look for and (3) what I am doing.

Knowing that mathematical word problem solving models should act as a guide to help students engage in a thoughtful thinking process, and not as steps to follow in an obligatory, routine and strictly sequential way, there is a need to investigate more specifically how the transition from theory to practice takes place. The study presented here, which is part of a broader research project (Goulet-Lyle 2018), has as its major goal the exploration of the possible consequences of using this kind of sequential method on students' com- prehension of mathematical word problems. In the following sections, the theoretical and empirical background of the study are examined, leading to the research questions and hypotheses. Then we present the research method, as well as the main results. Finally, we discuss the theoretical, methodological and practical implications.

\section{Theoretical background}

Mathematical word problem solving is made up of two main processes, namely comprehension and solution, which intimately interact in a complex way. As stated by Pólya (1973),

Trying to find the solution, we may repeatedly change our point of view, our way of looking at the problem. We have to shift our position again and again. Our conception of the problem is likely to be rather incomplete when we start the work; our outlook is different when we have made some progress; it is again different when we have almost obtained the solution (p. 5).

These changes in position that occur throughout the process of solving the problem explain why comprehension and solution are in such synergy.

\subsection{Comprehension}

In general, while comprehension is commonly defined as the construction of mental representations, the nature of these representations is explained differently according to various authors, based on their theoretical positions. In the context of this study, we focus on the development of two different but complementary levels of mental representation, namely situation models and problem models (Coquin- Viennot and Moreau 2007; Moreau and Coquin-Viennot 2003; Nathan et al. 1992; Reusser 1990; Staub and Reusser 1995; Thevenot and Oakhill 2005; Thevenot et al. 2007; Voyer 2006). Several authors highlighted the importance of a non-mathematical representation ${ }^{2}$ in the initial phase

\footnotetext{
${ }^{2}$ A non-mathematical representation is an episodic model of the situation described in the problem statement, allowing the solver to have a richer understanding of the story (who the characters are, what their actions and feelings are, where the story takes place, etc.), without directly contributing to solving the problem.
} 
of the problem solving process, that is a more qualitative representation in which the problem is presented, which refers to what many call the "situation model" (Kintsch 1998; Moreau 2001; Nathan et al. 1992; Porcheron 1998; Reusser 1990; Staub and Reusser 1995; Verschaffel et al. 2000; Coquin-Viennot and Moreau 2007; Voyer 2006). Constructing a situation model allows the solver to fill in the gaps left in the problem statement and to represent, in familiar and personal terms, the context around the problem. Since the primary objective is to solve the problem mathematically, the solver can take advantage of this qualitative mental representation to build a more goal-oriented and more formal representation that considers the numerical data. This more formal representation oriented to a mathematical perspective is known as the "problem model" (Kintsch and Greeno 1985). The problem model corresponds to the understand- ing of the logico-mathematical relations between the data and the mathematical procedures to be put in place in order to translate the statement of the problem into a mathematical model (Kintsch and Greeno 1985; Nathan et al. 1992). Therefore, the problem model is not represented in terms of mathematical symbols, whereas the mathematical model is. The solution process, which includes the construction of a mathematical model, usually follows the comprehension process (situation model and problem model).

Authors who studied the concepts of situation and problem models have highlighted the need to establish links between the explicit problem data and the solver's personal knowledge in order to reach a level of understanding sufficient for successful mathematical resolution (Kintsch 1998; Österholm 2006; Reusser 1990; Van Dijk and Kintsch 1983). This idea of making connections can be associated with a level of understanding that goes beyond the information presented explicitly in the statement, which is known as inferential understanding.

In the context of reading, an inference is produced when information that was not explicitly stated in the text is activated (St. George et al. 1997), either by making links between the information presented, or by recalling previous knowledge of the subject (Cain and Oakhill 1999; Giasson 2007). In other words, an inference is a piece of information or knowledge that is not given in the written communication, but is mentally constructed by the reader (McKoon and Ratcliff 1992; Tennent et al. 2008). Inferences serve to ensure the coherence and completeness of the mental representation, both locally, between the different textual units (propositions, sentences, paragraphs) and globally, referring to the understanding of the text as a whole (Martins and Le Bouédec 1998). "In the absence of inferences, the comprehension of a text would be limited to the elaboration of juxtaposed islands of significance" [En absence d'inférences, la compréhension se limite à l'élaboration d'îlots de signification juxtaposés] (Observatoire national de la lecture 2005, p. 16). According to Davoudi (2005), the ability to generate inferences is the cornerstone of reading proficiency: any text, no matter how complex, requires inferences to give the reader access to true understanding. The remarks of Yuill and Oakhill (1988) are consistent with those of Davoudi (2005), arguing that even simple texts demand the production of inferences in order to be well understood. In short, two elements make it possible to define clearly the concept of inferences used in the context of reading: (1) the action to go beyond the explicit information, and (2) the action to establish links, either between the information jn the text itself, and/or with the reader's previous knowledge.

In the following sections, we further delineate and sup- port the relationship between inferential understanding and situational and problem models of mathematical word problems. 


\subsubsection{Inferential understanding in the context of solving mathematics problems}

We derive from the above-mentioned definitions that the situation model is composed of a double structure including (1) the elements and relationships being directly, and explicitly, derived from the text by the reader, which is called the text base, and (2) the inferences generated based on the reader's previous knowledge and experience (Geiger and Vantine 2006; Kintsch 1998; Nathan et al. 1992; Voyer and Goulet 2013). Several authors explicitly mention the role of inferences in the process of constructing a situational model (Best et al. 2008; Brandao and Oakhill 2005; Eason et al. 2012; Geiger and Vantine 2006; Graesser et al. 1994; Kintsch 1998; Kintsch and Greeno 1985; Nathan et al. 1992; Van Dijk and Kintsch 1983; Voyer and Goulet 2013). As an example, Kintsch and Greeno (1985) state that the situation model "includes inferences that are made using knowledge about the domain of the text information" (p. 110). Other authors propose definitions of the situation model that imply the existence of the inferential process, without explicitly mentioning the concept of inferences. This is, for example, the case of Fagnant et al. (2003), who emphasize that the construction of the situation model requires some knowledge of the phenomenon involved in the situation described. These authors add that beyond possessing the knowledge required to infer information, it is essential for it to be activated. Such statements clearly fit into the inferential process that requires not only access to knowledge in relation to textual information, but also the awareness of having to recall that knowledge (Cain et al. 2001). For his part, Kintsch (1998) goes beyond the idea that inferences are necessary for the construction of a situational model, by arguing that situation models are a form of inference. However, for some word problems, where all the details as well as the general structure are made perfectly explicit, the situation model coincides with the text base (Kintsch 1998). All of this leads us to understand that creating a situation model is actually going beyond literal comprehension to access inferential understanding. Thus, the student engaged in a process of generating inferences is thereby engaged in a process of con- structing a situation model: when (s)he produces an inference, (s)he is working on the creation of a situation model. Regarding the problem model, achieving this level of representation is made possible by understanding the logico- mathematical relationships among the problem data. Nathan et al. (1992) point out that these relationships among data may be implicit, and hence absent from the text base. When this is the case, these relations must then be inferred by the solver from the situation model. According to Kintsch and Greeno (1985), the development of a problem model requires eliminating the non-essential propositions of the text base, while inferring critical information that is missing from it, for instance, identifying essential numerical data for the appropriate resolution of the problem.

\subsubsection{Types of inferences in the context of mathematical word problem solving}

In our study, we distinguished three categories of inferences, each playing a different role in solving a word problem. Inspired by the categorization proposed by Dupin de Saint- André (2011), we distinguished inferences as "necessary", "unnecessary", and "counterproductive" for the solution of the problem. More specifically, the inferences deemed necessary are those used to understand the data in the problem statement being directly related to the mathematical resolution of the problem. Without the production of these inferences, the solver cannot reach the solution. Among these inferences deemed necessary for a successful solution, we distinguish between (1) inferences allowing the solver to derive an element involving quantitative information and (2) inferences allowing the solver to release a qualitative information element. Quantitative information refers to numerical data and qualitative information to non-numerical data. For example, consider the following problem:

Sophie is a great runner. Soon, she will participate in an important competition where she wants to 
win the gold medal. In order to be prepared, she trains on an outdoor track that is located near her home. The track is $2 \mathrm{~km}$ around. Sophie makes 4 laps each day, every day of the week except Saturday. She also swims $1 \mathrm{~km}$ every Thursday. How many kilometers does Sophie run on this track a week?

To successfully solve this problem, the solver must pro- duce a necessary inference: the number of days that Sophie runs a week. This numerical information element is not presented explicitly. If Sophie runs every day except Saturday, it means that she runs 6 days a week, because a week has 7 days.

Inferences deemed unnecessary are those which, while providing a richer understanding of the story around the problem, are not specifically oriented toward its resolution. Rather, these inferences enable the student to better under- stand who the characters are, what their actions and feelings are, and where the story unfolds, for a better understanding of the context. In the problem presented above, a student might infer that Sophie wants to be on the top of the podium. This inference could be produced based on the information "She wants to win the gold medal". This new information would allow the student to represent the story in more detail, to better understand Sophie's aspirations, without providing any extra information that is helpful for mathematical modeling. Whether this inference is produced or not, it should not impact the resolution of the problem.

Finally, an example of a counterproductive inference would be to infer that because Sophie is swimming on Thursdays, she does not run on that day. This inference is to be avoided since it would cause the solver to move away from the proper modeling of the problem, which is that Sophie runs 6 days a week and not 5 days.

This classification was used to develop our assessment of the inferential understanding of mathematical word problems. It is important to note that the problems we were interested in were those whose mathematical resolution requires the production of at least one reading inference to arrive at the solution. In other words, these are problems for which the text base is not enough. At least one necessary inference must be produced in order to correctly model the situation described in the problem.

Considering the nature of our research objective, we chose to assess the mathematical word problem comprehension of students who had been previously taught the 'what I know, what I look for' method, by judging their level of literal and inferential understanding. The rationale for this choice, based on the role of inferences in this method in particular, is presented in more detail in Sect. 3.2.

\section{Empirical background}

\subsection{Main results of the first phase: online questionnaire}

In the first phase of our research project, we examined our main research question by analyzing the responses of 143 Quebecer elementary school teachers who completed an online questionnaire describing their practice regarding word problem solving methods ${ }^{3}$ (Goulet-Lyle 2018). Various elements that emerged from the results of this first phase of our project have highlighted the existence of a gap between what research advocates and what is practiced in the Quebecer classrooms. First, when teachers were asked how they present a mathematical problem solving method to their students,

3

This first phase was conducted after a smaller exploratory stage in which we interviewed ten teachers with the main goal of identifying different profiles regarding teaching practices related to mathematical problem solving methods. 
one-third ${ }^{4}$ reported that their students had to follow the above-mentioned 'what I know, what I look for' method and that they demanded that all the steps of the sequence be applied systematically in the same order as they were presented and documented accordingly in their written notes. This practice refers to a process that can be defined as sequential and inflexible. Indeed, since the steps of the model cannot logically be adapted to all problems (Reys et al. 2012), students must learn to make choices about the relevant steps to be taken for a given problem (Ontario Ministry of Education 2006). Moreover, the chosen steps should be addressed cyclically and iteratively (Fagnant et al. 2003; Greer 1997; Pólya 1945; Verschaffel et al. 2000). Like Reusser (1990), who explains several kinds of student errors in solving mathematical word problems by the educational culture in which this activity takes place, we justified part of the gap observed between research-based findings and recommendations, on the one hand, and teachers' teaching practice, on the other hand, by the fact that teachers require their students to solve problems following a predefined and inflexible sequence of steps.

Secondly, the finding that over $60 \%$ of teachers who use the 'what I know, what I look for' method in their classes think that the greatest benefit of this method is for students to solve problems step-bystep, further reinforces previous statements indicating a discrepancy regarding the cyclical and iterative nature that should be attributed to the problem solving process. It is important to note that it is not the method itself that creates a gap between research and practice, but the way in which it is presented and used in the teachers' mathematics lessons. Stated boldly, instead of promoting the development of a planful, thoughtful and flexible approach to word problem solving, these teachers' instructional practice rather focused on the memorization and routine application of a strict, inflexible and ritual procedure. Therefore, we wanted to study the possible consequences of the imposition of such a sequential method.

\subsection{Consequence of the observed gap}

Our hypothesis was that the imposition of the 'what I know, what I look for' method has a negative effect on students' understanding of word problems.

Thus, on the research side, as stated in Sect. 2.1, the understanding of mathematical word problems is described and interpreted in terms of the situation model and the problem model that the solver is constructing and the inferential processes in which (s)he engages (Kintsch 1998; Österholm 2006; Reusser 1990; Van Dijk and Kintsch 1983). On the practical side, the 'what I know, what I look for' method seems to focus particularly on the search for explicit data, and conversely, a reduced attention to the generation of inferences to reveal the implicit data of the problem. From this perspective, we believe that the majority of students who are asked to use this method break the statement into segments to complete the 'what I know' section, in which they copy the text's propositions that are explicitly written. Consequently, the main focus is on the literal understanding of the problem statement $^{5}$, which means that it is limited to an explicit level (identification) (Campion and Rossi 1999; Giasson 2003).

This hypothesized problem solving behavior is not only supported by teachers who declared that they do not require their students to include the implicit data in the 'what I know' section (Goulet-Lyle 2018), but also by writings on problem solving that state that, when formally taught, problem solving methods may lead students to focus more on the method provided than on mathematical concepts or under- standing the problem's data (Ontario Ministry of Education, 2006). As a result, students' comprehension may be limited to the literal level, not allowing for inferential understanding to be

\footnotetext{
${ }^{4}$ The other two-thirds of teachers do not oblige their students to follow the diferent steps in a specifc order.

${ }^{5}$ When the answer to a question is "semantically equivalent to a part of the text or synonymous to a part of the text" (Giasson 2003, p. $266)$, then it is a question of a literal understanding.
} 
achieved, which is the level of understanding sought in order adequately to solve a word problem.

\section{Research questions and hypothesis}

In light of data collected in the exploratory first phase of our research project, involving interviews (exploratory phase) and questionnaires (first phase), the general problem identified in this study was a lack of knowledge about the consequences of teaching practices that require students to use a problem solving method, namely the 'what I know, what I look for' method, which can be defined as sequential and inflexible.

The main question was stated as follows: Is fourth grade students' level of understanding of mathematical word problems influenced by the use of the 'what I know, what I look for' method? This question was further split into three sub-questions:

1. Is there a difference between the students who use the method and those who do not use it in terms of their level of literal comprehension?

2. Is there a difference between the two groups of students in terms of their level of inferential understanding?

3. Is there a difference between the two groups of students in terms of their level of understanding of necessary and unnecessary inferences?

Given the theoretical and empirical background of our study, we anticipated that the imposed use of the method 'what I know, what I look for' would limit the inferential understanding of students, which refers to an understanding of the implicit information.

\section{Method}

Considering the nature of our question and accompanying hypothesis, a comparative study was conducted, the objective of which was to compare two groups with each other (Fortin et al. 2006). A quantitative methodology involving a large and representative sample of classes was chosen, allowing us to determine if there are differences between the two groups that were not due to the particularities of the students and teachers of those classes.

No intervention was introduced, except for the method 'what I know, what I look for' which was imposed on one of the two groups of students. We compared the levels of understanding achieved by these two distinct groups of students: (1) an experimental group on which the method was

Fig. 1 Problem 1 presented in version 1 (imposed method)

\begin{tabular}{|c|}
\hline \begin{tabular}{l} 
To celebrate Mother's Day, Sandrine and her twin sisters go to the store to buy a gift for their \\
mother. They want to offer her a hot air balloon ride. If the price of the ride is $\$ 45$ per person, \\
and they wish to accompany their mother, how much will they pay for this experience? \\
\hline What I look for...
\end{tabular} \\
\hline $\begin{array}{c}\text { What I do... } \\
\text { (calculations, my work) }\end{array}$ \\
\hline
\end{tabular}


imposed and (2) a control group for which this was not the case. The main difference between the two conditions is that the experimental group was experimentally obliged to solve the problems using the method by completing the four sections that were provided on each page of the test. The control group had to solve exactly the same problems, but without having the method imposed in any way, as the control students received only a blank sheet of paper to use in solving the problems. The expected impact of this difference on students' problem solving processes was for the experimental group to focus more on the 'what I know' and 'what I look for' sections by paying more attention to selecting information written explicitly in the text, and less attention to the non-explicit information that would be useful in constructing an inferential understanding of the problem. We attempted to highlight the differences between the two groups in terms of their levels of general, inferential, and literal comprehension.

\subsection{Participants}

Considering that the first phase of the study was restricted to elementary school teachers from third to sixth grade, we decided to work with students belonging to one of these grades. More specifically, we decided to work with fourth graders. Participant selection was done using a non-probability sampling method called accidental sampling, in which participants are selected on the basis of specific criteria (Trudel and Antonius 1991). In our case, the participating classes had to meet two specific criteria: (1) be a fourth grade class and (2) use the method 'what I know, what I look for' for teaching mathematical problem solving. A total of 14 fourth-grade classes from eight different schools in the province of Quebec were involved in the second phase of the project, representing a sample of 278 students. The experimental group (imposed method) consisted of 137 students, while the control group (no imposed method) had 141 students. Students from each class were randomly assigned to one or the other group.

\subsection{Tasks and procedure}

The materials consisted of two self-made tests completed by all students, corresponding to tasks A (solution of problems) and B (comprehension of problems). Task A consisted of solving four mathematical word problems. Two different versions were randomly distributed to the students. In each of the participating classes, half of the students randomly received version 1 of the test, while the other half received version 2. The students who received version 1 formed the experimental group and those who received version 2 formed the control group.

This first task was designed to engage students in a writ- ten problem solving process and then assess their level of understanding. Regardless of the version received, all students were asked to solve the same four problems. For version 1, a problem statement was presented at the top of each page, and listed below were the four sections of the 'what I know, what I look for' method. The students were instructed to complete the four sections. With respect to version 2, no specific instructions were given to students as to the method to be used. Each statement was also presented on a separate page of the questionnaire followed by the instruction 'show your work'. No sections were drawn; it was an empty page. In other words, for these students, no method was imposed. The four problems are problems in which the text base on its own is not sufficient; one or more inferences need to be produced in order to model correctly the situation described in the problem statement. Figure 1 presents an example of problem 1 in the imposed version.

In task B, students were asked to answer a test designed to assess their level of understanding of the 
Fig. 2

Comprehension test related to problem 1 (task B)

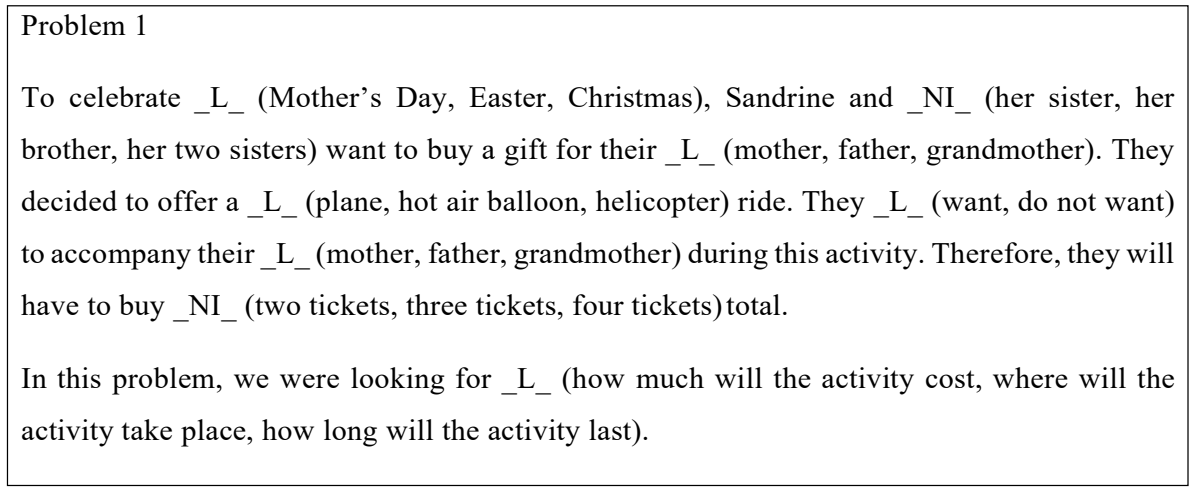

test was used, in which students had to choose one of three choices to fill each missing space. According to Leiss et al. (2010), this type of test provides a quick measure of students' reading comprehension. Considering our need to obtain a reading comprehension score for different types of questions (unnecessary inference questions, necessary inference questions, and literal questions), the questionnaire had to include a large number of questions. However, since students also had to solve problems before perform- ing the comprehension test, a time constraint had to be taken into account.

The comprehension test was constructed from the four word problems used in task A. For each problem, a text with seven or eight multiple-choice questions was presented to tell the story of the problem. For each question, there were three answer choices, only one of which was correct. To choose these answers correctly, students sometimes had to produce inferences, while in other cases identifying explicit information was sufficient. In other words, some questions corresponded to information that was not explicitly presented in the word problems, while others corresponded to information that had been explicitly presented. Specifically, for each story corresponding to one of the four word problems solved in task A, the student had to answer questions either by identifying explicit information or by generating 'unnecessary inferences' and 'necessary inferences', as defined previously in the theoretical framework. Of the 29 questions included in the test, 18 corresponded to literal questions while 11 were inferential questions. Five of the 11 inferential questions were 'necessary inferences' and six were 'unnecessary inferences'. Figure 2 presents the comprehension test related to problem 1. For each question, we indicate if it is a literal question (L), a 'necessary inference' (NI) or an 'unnecessary inference' (UN). Problem 1 did not include 'unnecessary inference' questions.

It is important to note that task A (solution of problems) was different for students of the experimental and control group, but task B (comprehension of problems) was the same for all students. The two tasks were performed by the students in one meeting, lasting $60 \mathrm{~min}$. The meeting took place in their respective classrooms, during the spring.

\section{Results}

No results are associated with task A (solution of problems), since the goal of this first task was merely to place students in a position of problem solving, with or without the imposed use of the 'what I know, what I look for' method. Therefore, task A was only a prerequisite for task B, which was designed to assess the level of understanding of the word problems solved.

Using the data obtained in task B (comprehension of problems), we attempted to determine the effect the method has on students' comprehension when it is imposed on them. The test included 29 
questions. To determine whether the level of understanding of problem statements is influenced by the imposition of the 'what I know, what I look for' method, we performed independent sample t-tests to verify whether there was a difference between the averages of the two groups. In doing so, we wanted to know whether being part of one of these two groups has an influence on the dependent variable studied, the level of general comprehension achieved. Table 1 presents the descriptive statistics for this first analysis.

It should be noted that 14 of the $141(9.9 \%)$ students who randomly received version 2 of the problem solving test, that is, the version for which no method was imposed, spontaneously chose to solve at least one of the four problems using the 'what I know, what I look for' method, which happens to

Table 1 Descriptive statistics of the general comprehension score according to the imposition, or not, of the 'what I know, what I look for' method

\begin{tabular}{lccl}
\hline & N & Mean & $\begin{array}{l}\text { Standard } \\
\text { deviation }\end{array}$ \\
\hline General comprehension score (out of 29) & & \\
Method imposed & 137 & 25.03 & 3.70 \\
Method not imposed & 141 & 24.89 & 2.93 \\
\hline
\end{tabular}

Table 2 Descriptive statistics for the four sub-variables

\begin{tabular}{lrrl}
\hline $\begin{array}{l}\text { Score in understanding according to the } \\
\text { method used }\end{array}$ & $\mathrm{N}$ & Mean & $\begin{array}{l}\text { Standard } \\
\text { deviation }\end{array}$ \\
\hline $\begin{array}{l}\text { Literal comprehension score (out of 18) } \\
\text { Method not imposed }\end{array}$ & 141 & 16.72 & 1.87 \\
$\quad 137$ & 16.71 & 2.10 \\
Method imposed & & \\
Inferential comprehension score (out of 11) & 141 & 8.16 & 1.66 \\
Method not imposed & 137 & 8.32 & 2.01 \\
Method imposed & 141 & 4.89 & 1.02 \\
Inferential-not-necessary comprehension score (out of 6) & \\
Method not imposed & 136 & 4.92 & 1.08 \\
Method imposed & 141 & 3.28 & 1.18 \\
Inferential-necessary comprehension score (out of 5) & \\
Method not imposed & 137 & 3.44 & 1.24 \\
Method imposed & \multicolumn{3}{l}{} \\
\hline
\end{tabular}


be the method normally requested in their classes. However, of these 14 students, only four solved all four problems using the 'what I know, what I look for' method. We considered that the control students chose to use the method when there was evidence of the four boxes (or any kind of sections) with written information serving the purpose of answering the four typical questions: What do I know? What am I looking for? What do I do? What is my answer? If the student wrote down only the four questions, without creating sections, we considered this as a use of the method as well.

By observing the descriptive data, we can see that the averages of the two groups are extremely close. The result of the $t$ test was not statistically significant, since the calculated probability is 0.722 , which corresponds to a value greater than the fixed error threshold of $0.05, \mathrm{t}(276)=-0.357, \mathrm{p}=$ 0.722 .

To further investigate the effect of the method on students' level of comprehension, we conducted additional tests, all with the method used as the independent variable. Considering the categorization of inferences chosen in our study, the inferential understanding variable was refined to determine whether there is a difference between students in the two groups in terms of their level of understanding of necessary inferences and unnecessary inferences. Using these additional analyses, we attempted to answer the following four sub-questions:

1. Is there a difference between students in the two groups in terms of their level of literal comprehension?

2. Is there a difference between students in the two groups in terms of their level of inferential understanding?

3. Is there a difference between students in the two groups in terms of their level of inferentialnecessary under- standing?

4. Is there a difference between students in the two groups in terms of their level of inferential-notnecessary understanding?

Table 2 presents the descriptive statistics for these four analyses.

These four $\mathrm{t}$-tests were all non-significant $[\mathrm{t}(276)) .=0.064, \mathrm{p}=0.949, \mathrm{t}(276)=-0.714, \mathrm{p}=$ $0.476, \mathrm{t}$

$(275)=-0.259, \mathrm{p}=0.796, \mathrm{t}(276)=-1.115, \mathrm{p}=0.266]$.

The averages are again extremely similar, reinforcing our previous interpretation: For the students of our sample, there was no difference in their level of understanding, whether the 'what I know, what I look for' method was imposed or not. Moreover, the standard deviation results also show that the distribution of the comprehension scores is similar for both groups, meaning that we observed a similar amount of variance in our sample, regardless of the group (with or without the imposed method). 
To summarize, we could not find any differences between the two groups in terms of understanding the problem statements for literal and inferential comprehension. Since the averages are virtually identical for both groups of students, we had to reject our first hypothesis that using the method 'what I know, what I look for' limits the inferential understanding of the students. On the other hand, for the students of our sample, it did not aid in a better understanding either. In other words, the method did not seem to have any impact on the comprehension of the word problems for the 278 students who participated in our study. However, the fact that only 4 out of 14 students who chose to use the method decided to use it for all problems led us to hypothesize that the majority of students question its general efficiency in terms of time and energy. We investigated this hypothesis in another phase of our research program, by administering a semi- structured interview to 104 students, from the 14 Quebecer classes (9-10 years old) (Goulet-Lyle 2018). The main goal of these interviews was to understand why students decide to use or not to use the 'what I know, what I look' for method in teaching or testing settings wherein this method is not imposed on them. First of all, it is worth noting that no students mentioned using the method with- out utilizing the four sections typically associated with it, which supports our previous interpretation regarding the number of students from the control group who used it spontaneously. The collected data indeed showed that the main reason reported by the 90 students who chose not to use this method to solve the problems presented in task A (solving test) was because they considered that the method was useless. Actually, 23 out of the 90 students gave this as the main explanation for their unwillingness to use the method. Below we give two such explanations:

"Even if I write what I know and what I look for, it's already written [in the text], so it does not change any- thing. This is not helpful."

"It does not really help me to do the math. I have already tried [the method] and I still did not succeed in [solving the problem]. It did not help much. It does not work. [...] I think it's a bit useless [for me], but for others, it can be useful."

We propose three hypothetical explanations why the averages for both groups of students are very close. Our first hypothetical explanation is based on the completion of the 'what I know' and 'what I look for' sections by the students of the experimental group. Based on the interviews of teachers during the exploratory phase, we already knew that some students engage in a problem solving approach by starting with the 'what I do' section. That means that the sections 'what I know' and 'what I look for' are completed only after the problem is solved and possibly understood. For these students completing these two initial sections is only an additional task that is not helpful for the understanding and solution of the problem. Thus, when these two sections are completed after the fact, it is not surprising that the use of the method does not influence the level of understanding. Indeed, such use can be compared to a non-use of the method.

Our second hypothetical explanation is related to the problem solving habits of the students in the control group. Since our sample was composed exclusively of students whose teachers value the method 'what I know, what I look for', it is reasonable to think that many students of the control group remained biased to the socio- mathematical classroom culture in which they operated on a daily basis, that is to say to solve problems by filling in the sections of a method chosen by the teacher. Even though the written notes of these students did not reveal that they had followed the 'what I know, what I look for' method (except in 14 cases, as reported above), we cannot exclude that in a significant number of cases they might have mentally applied (parts of) that solution method during their solution process. As a result, the fact that all students in our sample share a similar problem solving experience 
that they carry with them throughout the test, in our opinion, may also help to explain why the averages of the experimental and control groups are similar too.

Finally, it is possible that our results suffer from a ceiling effect. More precisely, the analysis of the distributions of the scores indicate that for the variable 'literal comprehension score', most students got a perfect score, which makes it difficult to see any difference between the two groups.

\section{Conclusion}

In this study, we were interested in knowing if students' level of mathematical word problem understanding is influenced by the imposed use of a popular method, known as the "what I know, what I look for' method, presented in many elementary schools of the province of Quebec. We assessed the literal and inferential understanding of 278 fourth grade students after solving four mathematical word problems, with or without the 'what I know, what I look for' method imposed to solve the problems. To determine whether the level of understanding of mathematical word problems is influenced by the imposition of the method, we compared the performance of an experimental group that received the explicit instruction to solve all problems using the 'what I know, what I look for' method and a control group that did not receive such an instruction, on a comprehension test involving literal and inferential questions.

Results showed that for the students of our sample the imposition of the method does not seem to have affected their understanding of the problem. We are aware that one should be cautious about generalizing our results and conclusions towards students from other age levels or different educational backgrounds as well as towards other (sequential stepwise) methods for word problem solving. How- ever, based on our analysis of the research literature and our own research findings we do believe that our results and conclusions may also apply to similar populations and similar problem solving methods. As an example, the UPSE method, which is the acronym for Understand, Plan, Solve, and Evaluate, described by Bruun (2013), is another method that was derived from Pólya's model for solving mathematical problems. The available literature on this method suggests that students must complete four sections that are very similar to those proposed by the "what I know, what I look for' method. The 'what I know, what I look for' method is only intended to be a concrete example of the observed gap between research and practice. This research project therefore does not focus on this method per se, but rather on all methods presenting two specific characteristics, namely (1) being a sequential method and

(1) focusing on explicit information.

Our results lead us to argue that how mathematical problem solving activity is addressed in the Quebecer upper elementary classrooms departs from the dual purpose of mathematical problem solving activity, namely developing students' problem solving skills and new mathematical knowledge (Dionne and Voyer 2009). In our opinion, it is, rather, directed towards the implementation of a resolution strategy being centered on the application of an algorithm in order to reach the expected mathematical solution. 
By imposing a specific method on students, and requiring that it be used in a specific way, the problem solving teaching time is devoted more to learning a series of steps than to developing strategies and skills that shape students into good solvers. For some students, remembering how to use the method imposed on them, for example, knowing what to put in each section of the method 'what I know, what I look for', can be a problem. For these students, the energy they deploy is therefore not related to their skills and knowledge as a solver, but rather their ability to memorize and execute a learned sequence. As a result, this practice does not allow students to develop into good solvers, and it can even be detrimental to some students for whom the method itself is a problem. ${ }^{6}$

In our opinion, teaching students a unique method and imposing this method upon them is not effective, in the sense that it does not help them to understand and solve problems that are different from the ones they are used to. Further- more, by asking students to solve problems using a series of predetermined steps, students do not have the chance to develop and apply certain metacognitive strategies. For example, a common reflection that may be associated with a metacognitive strategy would be: 'Have I adjusted my method to the task at hand?' (Ministère de l'Éducation, du Loisir et du Sport 2006). However, this question does not apply to students who are not free to make this choice because a method was imposed on them before even knowing the problem to be solved; Nor can they adjust it as they are required to complete each step systematically. In this sense, it is reasonable to think that imposing a system- atic method deprives students of their control on how to approach the resolution of a problem, and as a result, may limit the mobilization of metacognitive strategies. The mobilization of such strategies can make the difference between becoming an effective and an ineffective solver.

Teaching and learning a problem solving method can be effective in solving routine problems carefully chosen by the teacher to fit into the preferred method in the class- room. Consequently, as soon as the student is confronted with a different problem, he can be caught off guard. This is what Mayer (1998) explains when he states that students often have difficulty with transfer activities, which is when they have to apply what they have learned to a new situation. Speaking more specifically about problem solving in mathematics, he adds that: "On routine problems - that is, problems that are like those they have already learned to solve- they excel; on nonroutine problems - i.e., problems that are not like any that they have solved in the pastthey fail" (p. 49).

That is why it seems essential to us that teachers under- stand the role of problem solving methods in the classroom. Why are methods presented to students? A simple answer would be to help students think about problems (Pólya 1945). The methods should therefore be presented as tools or reference guides from which students can ask themselves the right questions to address the problems they encounter (Ontario Ministry of Education 2006; Reys et al. 2012). Often, it is not the method that is problematic, but rather the way it is used. In this sense, it must be ensured that the method is introduced in the classrooms to encourage students to reflect, not to limit their creativity. Thus, in order to bring research closer to practice, the mathematical problem solving activity must conform to the following: (1) give students the freedom of reflection manifested by a choice of what process to implement, and (2) train students to create a mental representation of the implicit data that can be generated by inferences.

\footnotetext{
${ }^{6}$ For example, using the 'what I know, what I look for' method can be a problem for some students who do not remember 'what goes in what section'.
} 


\section{References}

Best, R. M., Floyd, R. G., \& McNamara, D. S. (2008). Differential competencies contributing to children's comprehension of narrative and expository texts. Reading Psychology, 29(2), 137-164.

Brandao, A. C. P., \& Oakhill, J. (2005). How do you know this answer? Children's use of text data and general knowledge in story com- prehension. Reading and Writing, 18(7), 687-713.

Bruun, F. (2013). Elementary teachers' perspectives of mathematics problem solving strategies. The Mathematics Educator, 23(1), 45-59.

Cain, K., \& Oakhill, J. V. (1999). Inference making ability and its relation to comprehension failure in young children. Reading and Writing, 11(5), 489-503.

Cain, K., Oakhill, J. V., Barnes, M. A., \& Bryant, P. E. (2001). Com- prehension skill, inferencemaking ability, and their relation to knowledge. Memory \& Cognition, 29(6), 850-859.

Campion, N., \& Rossi, J. P. (1999). Inférences et compréhension de texte. L'Année Psychologique, 99(3), 493-527.

Coquin-Viennot, D., \& Moreau, S. (2007). Arithmetic problems at school: When there is an apparent contradiction between the situation model and the problem model. British Journal of Educational Psychology, 77(1), 69-80.

Davoudi, M. (2005). Inference generation skill and text comprehension. The Reading Matrix, 5(1), 106-123.

Dionne, J., \& Voyer, D. (2009). Conférence d'ouverture: 50 ans d'enseignement des mathématiques au Québec. Bulletin AMQ, 49(3), 6-26.

Dupin de Saint-André, M. (2011). L'évolution des pratiques de lecture à haute voix d'enseignantes expertes et leur influence sur le développement de l'habileté des élèves du préscolaire à faire des inférences (Thèse de doctorat inédite). Université de Montréal.

Eason, S. H., Goldberg, L. F., Young, K. M., Geist, M. C., \& Cutting, L. E. (2012). Reader-text interactions: How differential text and question types influence cognitive skills needed for reading com- prehension. Journal of Educational Psychology, 104(3), 515-528.

Fagnant, A., Demonty, I., \& Lejong, M. (2003). La résolution de problèmes: Un processus complexe de modélisation mathématique.Bulletin d'Informations Pédagogiques, 54(1), 29-39.

Fortin, M. F., Côté, J., \& Filion, F. (2006). Fondements et étapes du processus de recherche. Montréal: Chenelière Éducation.

Geiger, J. F., \& Vantine, P. T. (2006). Which textual representations are formed during reading or solving mathematical word problems? Psychology and Education, 43(3/4), 1-7.

Giasson, J. (2003). La lecture: De la théorie à la pratique. Boucher- ville: Gaétan Morin.

Giasson, J. (2007). La compréhension en lecture. Bruxelles: De Boeck. Goulet-Lyle, M. P. (2018). Méthodes de résolution de problèmes écrits de mathématiques présentées au primaire: Pratiques associées et effets de ces méthodes sur l'activité mathématique des élèves.

(Thèse de doctorat inédite). Université du Québec à Rimouski. Graesser, A. C., Singer, M., \& Trabasso, T. (1994). Constructing inferences during narrative comprehension. Psychological Review, 101(3), 371-395.

Greer, B. (1997). Modelling reality in mathematics classrooms: The case of word problems. Learning and Instruction, 7(4), 293-307. Kintsch, W. (1998). Comprehension: A paradigm for cognition. New York: Cambridge University Press.

Kintsch, W., \& Greeno, J. G. (1985). Understanding and solving word arithmetic problems. Psychological Review, 92(1), 109-129.

Leiss, D., Schukajlow, S., Blum, W., Messner, R., \& Pekrun, R. (2010). The role of the situation model in mathematical modelling - task analyses, student competencies, and teacher interventions. Journal für Mathematik Didaktik, 31(1), 119-141.

Martins, D., \& Le Bouédec, B. (1998). La production d'inférences lors de la compréhension de textes 
chez des adultes: Une analyse de la littérature. L'Année Psychologique, 98(3), 511-543.

Mayer, R. E. (1998). Cognitive, metacognitive, and motivational aspects of problem solving. Instructional Science, 26(1), 49-63. McKoon, G., \& Ratcliff, R. (1992). Inference during reading. Psychological Review, 99(3), 440-466.

Ministère de l'éducation, du loisir et du sport, (2006). Programme de formation de l'école québécoise, version approuvée. Québec: Gouvernement du Québec.

Moreau, S. (2001). La compréhension des énoncés de problèmes arithmétiques: Rôle du modèle de situation (Thèse de doctorat inédite). Université de Poitiers.

Moreau, S., \& Coquin-Viennot, D. (2003). Comprehension of arithmetic word problems by fifth-grade pupils: Representations and selection of information. British Journal of Educational Psychology, 73(1), 109-121.

Nathan, M. J., Kintsch, W., \& Young, E. (1992). A theory of algebra- word-problem comprehension and its implications for the design of learning environments. Cognition and Instruction, 9(1), 329389.

Observatoire national de la lecture. (2005). L'apprentissage de la lecture. http://onl.inrp.fr/ONL/garde/rapport. Accessed 18 Aug 2019. Ontario Ministry of Education. (2006). A guide to effective instruction in mathematics. Kindergarten to grade 6. Volume 2. Problem Solving and Communication. http://www.edugains.ca/resourcesLNS/ GuidestoEffectiveInstruction/GEI_Math_K-6/Guide_Math_K_6_Volume_2.pdf. Accessed 24 Oct 2018.

Österholm, M. (2006). A reading comprehension perspective on problem solving. In C. Bergsten \& B. Grevholm (Eds.), Developing and researching quality in mathematics teaching and learning (pp. 136-145). Malmö, Sweden: MADIF 5 (The 5th Swedish Mathematics Education Research Seminar).

Pólya, G. (1945, 1973). How to solve it. Princeton: Princeton University Press.

Porcheron, J. L. (1998). Production d'inférences dans la résolution de problèmes additifs (Thèse de doctorat inédite). Université de Paris.

Reusser, K. (1990). From text to situation to equation: Cognitive simulation of understanding and solving mathematical word problems. In H. Mandl, E. De Corte, S. N. Bennett, \& H. F. Friedrich (Eds.), Learning \& instruction: European research in an international context (Vol. 2, pp. 477498). Oxford: Pergamon Press.

Reys, R. E., Lindquist, M. M., Lambdin, D. V., Suydam, M. N., \& Smith, N. L. (2012). Helping children learn mathematics. New York: Wiley.

Schoenfeld, A. H. (1992). Learning to think mathematically: Problem solving, metacognition, and sense-making in mathematics. In D. Grouws (Ed.), Handbook for research on mathematics teaching and learning (pp. 334-370). New York: MacMillan.

St. George, M., Mannes, S., \& Hoffman, J. E. (1997). Individual differences in inference generation: An ERP analysis. Journal of Cognitive Neuroscience, 9(6), 776-787.

Staub, F. C., \& Reusser, K. (1995). The role of presentational structure in understanding and solving mathematical word problems. In C. A. Weaver, S. Mannes, \& C. R. Fletcher (Eds.), Discourse comprehension: Essays in honor of Walter Kintsch (pp. 285-306). Hillsdale: Lawrence Erlbaum Associates.

Tennent, W., Stainthorp, R., \& Stuart, M. (2008). Assessing reading at key stage 2: SATs as measures of children's inferential abilities. British Educational Research Journal, 34(4), 431-446.

Thevenot, C., Devidal, M., Barrouillet, P., \& Fayol, M. (2007). Why does placing the question before an arithmetic word problem improve performance? A situation model account. The Quarterly Journal of Experimental Psychology, 60(1), 43-56.

Thevenot, C., \& Oakhill, J. (2005). The strategic use of alternative representations in arithmetic word problem solving. The Quarterly Journal of Experimental Psychology Section A, 58(7), 1311-1323. 
Trudel, R., \& Antonius, R. (1991). Méthodes quantitatives appliquées aux sciences humaines. Montréal: Centre Éducatif et Culturel Inc.

Van Dijk, T. A., \& Kintsch, W. (1983). Strategies of discourse comprehension. New York: Academic Press.

Verschaffel, L., Greer, B., \& De Corte, E. (2000). Making sense of word problems. Lisse: Swets \& Zeitlinger.

Voyer, D. (2006). L'influence des facteurs liés à l'élève ou à l'énoncé sur la compréhension en résolution de problèmes écrits d'arithmétique. (Thèse de doctorat inédite). Université Laval.

Voyer, D., \& Goulet, M. P. (2013). La compréhension de problèmes écrits d'arithmétique au regard de l'habileté en lecture d'élèves de sixième année. Revue des Sciences de l'Éducation, 39(3), 491513.

Wilson, J. W., Fernandez, M. L., \& Hadaway, N. (1993). Mathematical problem solving. In P. S. Wilson (Ed.), Research ideas for the classroom: High school mathematics (pp. 57-78). New York: Macmillan Publishing Company.

Yuill, N., \& Oakhill, J. (1988). Effects of inference awareness training on poor reading comprehension. Applied Cognitive Psychology, 2(1), 33-45. 